\title{
Reactive magnetron sputtering of uniform yttria-stabilized zirconia coatings in an industrial setup
}

Steffen Sønderby, A. J. Nielsen, B. H. Christensen, K. P. Almtoft, Jun Lu, Jens Jensen, L. P. Nielsen and Per Eklund

\section{Linköping University Post Print}

\begin{abstract}
N.B.: When citing this work, cite the original article.
\end{abstract}
Original Publication:

Steffen Sønderby, A. J. Nielsen, B. H. Christensen, K. P. Almtoft, Jun Lu, Jens Jensen, L. P. Nielsen and Per Eklund, Reactive magnetron sputtering of uniform yttria-stabilized zirconia coatings in an industrial setup, 2012, Surface \&amp; Coatings Technology, (206), 19-20, 4126-4131.

http://dx.doi.org/10.1016/j.surfcoat.2012.04.007

Copyright: Elsevier

http://www.elsevier.com/

Postprint available at: Linköping University Electronic Press http://urn.kb.se/resolve?urn=urn:nbn:se:liu:diva-79708 
Reactive magnetron sputtering of uniform yttria-stabilized zirconia coatings in an industrial setup

S. Sønderby ${ }^{\mathrm{a}, \mathrm{b}, *}$, A.J. Nielsen ${ }^{\mathrm{b}, \mathrm{c}}$, B.H. Christensen ${ }^{\mathrm{b}}$, K.P. Almtoft ${ }^{\mathrm{b}}$, J. Lua ${ }^{\mathrm{a}}$, J. Jensen ${ }^{\mathrm{a}}$, L.P. Nielsen ${ }^{\mathrm{b}}$, and P. Eklund ${ }^{\mathrm{a}}$

${ }^{a}$ Thin Film Division, Department of Physics, Chemistry and Biology, IFM, Linköping University, SE-581 83 Linköping, Sweden

${ }^{b}$ Danish Technological Institute, Tribology Centre, Teknologiparken, Kongsvang Allé 29, DK8000 Aarhus C, Denmark

${ }^{c}$ Interdisciplinary Nanoscience Center (iNANO) and Department of Physics and Astronomy, Aarhus University, Ny Munkegade, Bldg. 1520, DK-8000 Aarhus C, Denmark

*Corresponding author. Tel: +45-7220 2795; Fax: +45-7220 1550; E-mail: stso@dti.dk

Keywords: Physical Vapor deposition (PVD); Solid Oxide Fuel Cell (SOFC); X-ray Diffraction (XRD); Electron Microscopy; Elastic Recoil Detection Analysis (ERDA). 


\begin{abstract}
Yttria-stabilized zirconia (YSZ) thin films were deposited by reactive magnetron sputtering in an industrial scale setup on silicon wafers as well as commercial NiO-YSZ fuel cell anodes. The texture, morphology, and composition of the deposited films were investigated as a function of deposition parameters. Homogeneous coatings could be deposited over large areas within the coating zone, which is important for industrial applications. The use of substrate bias during film growth was identified as a key parameter to promote less columnar coatings and made it possible to tailor the texture of films deposited on Si. Bias voltages $\leq-40 \mathrm{~V}$ resulted in highly $<200>$ textured YSZ films, intermediate bias voltages of $-50 \mathrm{~V}$ to $-70 \mathrm{~V}$ in $<220>$ textured films and high bias voltages $(\geq-90 \mathrm{~V})$ in a mixed orientation. In contrast, films grown on NiO-YSZ were seen to be randomly orientated when deposited at substrate bias voltages $\leq-30 \mathrm{~V}$. When bias was further increased the film took over the orientation of underlying substrate due to substrate template effects.
\end{abstract}




\section{Introduction}

Today, yttria-stabilized zirconia (YSZ) is the preferred material for electrolytes in solid oxide fuel cells (SOFCs) as it is an acceptable ionic conductor, electrical insulator, chemically inert and relatively cheap to produce. The major problem related to existing SOFCs is the rather high operation temperature of typically $800-1000{ }^{\circ} \mathrm{C}$ which results in increased reactivity of the cell core components and the use of expensive interconnect materials [1]. Therefore, a primary goal of SOFC development is to lower the operation temperature and thereby achieve greater flexibility in the choice of material for stack construction [2]. A common design for SOFCs is the anode-supported cell where the anode thickness is of the order of millimeters resulting in appropriate mechanical strength to support the rest of the cell. Typically, a tapecasting technique is applied for the production of the electrolyte on top of the anode support which results in electrolyte thicknesses below $50 \mu \mathrm{m}$ [3]. However, by applying a physical vapor deposition (PVD) technique it is possible to produce thin film electrolytes with thicknesses down to a few microns and thereby lower the operation temperature of the SOFC to an intermediate temperature domain of $500-700^{\circ} \mathrm{C}$, as the ohmic losses in the electrolyte will be minimized $[1,2,4]$.

Previous investigations have demonstrated laboratory scale deposition of YSZ thin films by techniques such as pulsed laser deposition (PLD) [5,6], chemical vapor deposition (CVD) [7], atomic layer deposition (ALD) [8], electron beam evaporation (PVD) [9], and magnetron sputtering $[10,11,12,13,14,15]$. In connection with scale-up potential and industry applications it is however important to address the deposition time and throughput to keep the cost low enough to be competitive, and at the same time the quality of the deposited coatings needs to be reproducible and uniform throughout the coating area of the entire production unit [2]. These requirements pose a challenge for up-scaling from the lab-scale to industrial-scale, in particular when depositing oxides by reactive sputtering which is known to cause hysteresis effect, non-uniformity of the films, and poor reproducibility [16]. Therefore, for 
implementation of magnetron sputtering in large-scale SOFC manufacturing, further work proving the technology in industrial setups is needed.

In the present paper, YSZ thin films are deposited in an industrial setup on both $\mathrm{Si}(001)$ and commercial NiO-YSZ SOFC anodes. The morphology and texture dependencies of substrate bias voltage and substrate type are investigated as well as the homogeneity of the coating on Ni-YSZ substrates. The deposited YSZ films are about $2 \mu \mathrm{m}$ thick and are shown to be homogenous over large coating areas within an industrial scale coating unit, meeting industrial requirements.

\section{Experimental details}

YSZ coatings were deposited by reactive pulsed DC magnetron sputtering using a CC800/9 SinOx coating unit from CemeCon AG. The coatings were deposited on both $\mathrm{Si}(001)$ substrates $\left(15 \times 15 \mathrm{~mm}^{2}\right)$ and porous NiO-YSZ fuel cell anode substrates (size ranging from $65 \times 65 \mathrm{~mm}^{2}$ to $130 \times 130 \mathrm{~mm}^{2}$ ). The substrates were mounted on a stage carrying out a twofold planetary rotation. Because of this planetary motion the distance between the cathodes and the substrate was continuously changing and at some points the substrate faced away from the cathode. The smallest distance between the cathodes and the substrate was $10 \mathrm{~cm}$ and the longest distance, while still facing the cathode, was $40 \mathrm{~cm}$. When mounting NiO-YSZ substrates, care has to be taken to avoid electrical point contacts that might lead to high currents which in combination with high temperature can result in a detrimental phase transformation in the YSZ known as electrochemical blackening [17]. Two metallic Zr-Y (86:14 at.\%) targets of size $88 \times 500 \mathrm{~mm}^{2}$ with $99.5 \%$ purity were sputtered in a $\mathrm{Ar} / \mathrm{Kr} / \mathrm{O}_{2}$ mixture atmosphere. $\mathrm{Kr}$ was added as a sputtering gas as its atomic mass is close to the atomic mass of $\mathrm{Zr}$ and $\mathrm{Y}$ which leads to increased momentum transfer that may be beneficial for the kinetics of film growth. The purity of all the applied sputtering and reactive gasses were 99.999\%. The chamber base pressure was lower than $1 \mathrm{mPa}$. The samples were pre-heated to 
approximately $500{ }^{\circ} \mathrm{C}$ which was also the temperature during the deposition. Ar and $\mathrm{Kr}$ gas flow rates were $320 \mathrm{sccm}$ and $100 \mathrm{sccm}$ respectively, and the $\mathrm{O}_{2}$ flow rate was approximately $70 \mathrm{sccm}$. The total chamber pressure was $0.4 \mathrm{~Pa}$ during sputtering. Deposition was performed with a power on each cathode close to $3000 \mathrm{~W}$. In order to vary the incident flux and energy of positively charged ions bombarding the growing film a pulsed DC bias with a frequency of $350 \mathrm{kHz}$ and a reverse time of $1 \mu \mathrm{s}$ was applied to the substrates. The films were deposited while running the system in the hysteresis transition region but close to metallic mode as this gave the highest deposition rate while obtaining stoichiometric films. In order to run the system in the transition region between the poisoned and metallic state of the targets, the cathode voltage was used as an oxygen partial-pressure feedback signal for controlling the reactive sputtering process. The deposition time was $1 \mathrm{~h}$ and $45 \mathrm{~min}$ while the total process including pumping, pre-heating, coating, and subsequent cooling lasted $4 \mathrm{~h}$.

X-ray diffraction (XRD) measurements in the $\theta-2 \theta$ geometry were performed with a Bruker D8 Discover diffractometer using $\mathrm{Cu} K \alpha$ radiation. Scanning electron microscopy (SEM, Nova 600 nanoSEM from FEI) was used to determine the film morphology as well as film thickness. Transmission electron microscopy (TEM) micrographs of film cross sections were done using a Tecnai $\mathrm{G}^{2}$ from FEI. Cross-section samples were prepared by mechanically polishing down to a thickness of approximately $55 \mu \mathrm{m}$ followed by ion milling using Precision Ion Polishing System (PIPS; Gatan) operated at $5 \mathrm{keV}$ and $5^{\circ}$ incident angle with argon ions and a final polishing step at $2 \mathrm{keV}$ for $10 \mathrm{~min}$.

The film composition was investigated with energy dispersive x-ray spectroscopy (EDS, manufactured by EDAX and analyzed by the EDAX Genesis software) and by time-of-flight energy elastic recoil detection analysis (ToF-E ERDA). The ToF-E ERDA was performed with a $40 \mathrm{MeV}{ }^{127} \mathrm{I}^{9+}$ beam, having an incident angle of $67.5^{\circ}$ with respect to the surface normal, and the recoils were detected at an angle of $45^{\circ}[18,19]$. The measured ToF-E ERDA data were converted into relative atomic concentration profiles using the CONTES code [20]. 
Due to limited mass resolution $\mathrm{Y}$ and $\mathrm{Zr}$ could not be separated in the ERD analysis. EDS allows distinguishing $\mathrm{Zr}$ from $\mathrm{Y}$, however, it is not accurate when measuring the concentration of light elements such as oxygen. Therefore, the two techniques complement each other well.

Large scale homogeneity testing of the deposited thin films was analyzed by EDS. NiO-YSZ anodes of size up to $130 \times 130 \mathrm{~mm}^{2}$ were placed at different heights in the coating unit throughout the coating height of $400 \mathrm{~mm}$ as shown in Figure 1. For substrates placed in the bottom, middle, and top of the coating height, EDS measurements were performed at three randomly chosen positions on the sample resulting in 9 positions in total. For each chosen position 3-4 EDS measurements were carried out. Multiple comparison procedures were performed by One Way ANOVA. A significance level of 0.05 was used. Thus, $\mathrm{P}$ values equal or less than 0.05 mean that the sample compositions are significantly different.

\section{Results and discussion}

\subsection{Deposition on $\mathrm{Si}(001)$}

YSZ films were deposited at different bias voltages ranging from floating potential to $-200 \mathrm{~V}$ while keeping all other parameters constant.

Figure 2 shows XRD $\theta-2 \theta$ diffractograms of YSZ films deposited at different bias voltages on $\operatorname{Si}(001)$ substrates at a substrate temperature of $500{ }^{\circ} \mathrm{C}$. For all depositions, the observed peaks correspond to cubic YSZ (ICDD JCP2 No. 82-1246). For films deposited at floating potential or a bias voltage of $-30 \mathrm{~V}$ or $-40 \mathrm{~V}$ the 200 peak is dominant, showing that these films have a pronounced $\langle 200\rangle$ texture. Films deposited at $-50 \mathrm{~V}$ to $-70 \mathrm{~V}$ have $<220\rangle$ texture and at applied bias voltages greater than $-70 \mathrm{~V}$ the films develop an equally mixed $\langle 111\rangle$ and $<220>$ texture.

The $<200>$ texture observed at low bias voltages can be explained by considering adatom binding energies. It has previously been described [21] that when the reactive gas is molecular 
oxygen and the adatoms are metallic $\mathrm{Zr} / \mathrm{Y}$ the (200) plane will have the highest number of nearest neighbors, hence the fastest growth direction will be [200] resulting in the $\langle 200\rangle$ texture. As the targets in the present study are sputtered in near-metallic mode, the adatoms are expected to be predominantly metallic and the explanation for the $\langle 200\rangle$ texture given in [21] is most likely valid also in the present work.

The $\langle 220\rangle$ texture observed at bias voltages of $-50 \mathrm{~V}$ to $-70 \mathrm{~V}$ is most likely an ion-induced effect due to increased kinetic energies of bombarding positively charged particles. The mixed $<111>$ and $<220>$ seen at bias voltages greater than $-70 \mathrm{~V}$ is similar to observations found in other studies $[10,22,23]$ and can be explained as a balance between ion-induced texturing and surface energy minimization as increased atom mobility promote the $<111>$ texture which minimizes the surface energy of YSZ following a partial transition from zone T to zone II in the zone model formalism [21].

In Fig. 2, a peak broadening and shift to lower angles is observed as bias voltage is increased above $-50 \mathrm{~V}$. This is most visible for the 220 peak as it has the highest intensity at $-50 \mathrm{~V}$ where the development sets in. Peak broadening is associated with smaller grain size and shifting of peak positions to lower angel is a result of compressive stress being induced in the film. Both are phenomena often observed when thin films are grown under intense ion bombardment.

Figure 3 shows SEM surface micrographs of the YSZ films deposited at bias voltages of -30 $\mathrm{V},-70 \mathrm{~V}$, and $-200 \mathrm{~V}$. For a bias of $-30 \mathrm{~V}$, the surface is clearly facetted while at $-70 \mathrm{~V}$ the surface shows a nodular morphology. At a bias voltage of $-200 \mathrm{~V}$ the surface has been scarred by the intense ion bombardment. The change from a facetted surface to nodular morphology is consistent with the change of texture from $\langle 200\rangle$ to $\langle 220\rangle$ as seen in Fig. 2. In fact, the facets observed at bias voltages $\leq-40 \mathrm{~V}$ is a direct illustration of the $\langle 200\rangle$ texture as the $\{111\}$ faceted crystal habit seen in Fig. 3.a is expected in this texture [24]. 
Figure 4 shows cross section SEM micrographs of YSZ films deposited at $-40 \mathrm{~V}$ (a), $-50 \mathrm{~V}$ (b), and $-200 \mathrm{~V}$ substrate bias (c). The film thicknesses range from $2.0-2.7 \mu \mathrm{m}$ giving deposition rates of $1.1-1.5 \mu \mathrm{m} / \mathrm{h}$. As the deposition time has been kept constant the difference in film thickness is a result of resputtering due to the ion bombardment resulting in lower deposition rate at increased bias voltage. Films deposited at $-40 \mathrm{~V}$ and $-50 \mathrm{~V}$ are clearly columnar with approximately $200 \mathrm{~nm}$ wide columns. All films deposited at bias voltages lower than $-200 \mathrm{~V}$ appears to be columnar, however, for the film deposited at $-200 \mathrm{~V}$ no columns are seen. This is expected since increased bias voltage and the resulting increased energy flux of bombarding ions increases nucleation rates and film density and inhibits the formation of columnar structures [25] as also seen in the present work.

\subsection{Deposition on NiO-YSZ anodes}

YSZ films were also deposited on commercial porous NiO-YSZ fuel cell anodes manufactured by tape-casting. The deposition parameters were the same as when depositing on $\operatorname{Si}(001)$.

Figure 5 shows cross-sectional SEM images of YSZ films deposited on NiO-YSZ anode substrates at floating potential (a) and substrate bias of -140 V (b). However, the effective bias is unknown, but lower than the set bias, as the NiO-YSZ substrate is an electrical insulator. Therefore, a direct comparison with films grown on $\mathrm{Si}(001)$ at absolute bias voltage values is not possible. All the grown films are columnar, as seen in earlier studies of YSZ deposited on NiO-YSZ substrates $[5,14]$. At floating potential the film is columnar with columns of width 100-200 nm ending in facets. Partly due to the substrate roughness the columns spread out resulting in a somewhat open structure. At increased bias voltage (Fig. 5.b) the YSZ film appears denser but is still columnar. The columns are around $1 \mu \mathrm{m}$ wide and subdivided into smaller columns as seen in TEM (Fig. 5.c). From the highly resolved image it is evident that 
no facets are seen at the surface. The much larger columns observed at high bias voltage can be explained by the increased adatom mobility due to the ion bombardment [25].

Figure 6 shows SEM micrographs of surfaces of uncoated and coated NiO-YSZ anodes. The substrate consist of sintered $\mathrm{NiO}$ and $\mathrm{YSZ}$ grains with an average size of a few $\mu \mathrm{m}$ as seen in Fig 6.a. The film grown at floating potential (Fig.6.b) is columnar with columns ending in facets. The underlying structure of the substrate is seen to be reproduced in the coating and the grooves and pores between the substrate grains are not covered properly. At $-140 \mathrm{~V}$ substrate bias (Fig 6.c) coarsening of the columns has taken place as also seen in the corresponding cross section SEM (Fig 5.b). This coating appears denser and covers the grooves and pores of the substrate to a much greater extent than observed at floating potential which is a result of the increased adatom mobility caused by the intense ion bombardment.

Figure 7 shows TEM micrographs and electron diffraction patterns of a film grown at $-50 \mathrm{~V}$ bias. Fig. 7.a shows the case in which the YSZ film grows on one of the YSZ grains in the NiO-YSZ substrate. The bottom electron diffraction pattern in Fig. 7.a stems from the substrate and due to the similarity of the diffraction patterns from the deposited YSZ film shown in the middle and top of Fig 7.a it is seen that the substrate and the film have the same crystallographic orientation. Fig. 7.b shows the YSZ film growing on one of the $\mathrm{NiO}$ grains also found in the NiO-YSZ substrate. Electron diffraction has been performed at the interface between film and the $\mathrm{NiO}$ grain and is seen inserted in the upper right corner of the figure. The diffraction pattern reveals that the YSZ film and the NiO substrate have the same orientation. TEM was also performed for the film grown at $-140 \mathrm{~V}$ and the trend of films growing with the same orientation as the substrate is also found in that case (data not shown).

Figure 8 shows TEM micrographs and electron diffraction patterns of a film grown at a substrate bias of $-30 \mathrm{~V}$ and the corresponding electron diffraction pattern of the substrate. The electron diffraction patterns show that there is no correlation between the film and substrate 
orientation and that the columns in the film are randomly oriented in contrast to the films deposited at higher bias.

High substrate bias is known to increase adatom mobility which enables the adatoms to move to sites where a preferential interaction with the substrate is possible [25]. This is likely to be the cause of the template effect of the substrate on the growing film seen at bias voltages $\geq-50$ $\mathrm{V}$ where local epitaxy on every individual grain in the NiO-YSZ substrate is observed. Compared to films deposited on $\mathrm{Si}(001)$ substrates films deposited on NiO-YSZ fuel cell anodes do not display any overall texturing. These results demonstrate the importance of choosing the actual fuel cell anode as substrate if the goal is to investigate the microstructure of the deposited electrolyte.

\subsection{Large scale uniformity of the deposited YSZ films}

From the chosen target composition it can be calculated that fully stoichiometric coatings theoretically will consist of 28.77 at.\% Zr, 5.48 at.\% Y, and 65.75 at.\% O. ToF-E ERDA measurements were performed and gave a film composition of 33 at.\% $(\mathrm{Zr}+\mathrm{Y}), 66$ at.\% $\mathrm{O}$, and a negligible Ar contamination showing that the films are fully stoichiometric. Performing EDS, using internal standards, on the same samples gave a sample composition of 8.5 at. \% $\mathrm{Y}, 31.8$ at.\% and 59.7 at.\% $\mathrm{O}$ which is a 0.9 times lower $\mathrm{O}$ content and 1.22 higher $\mathrm{Zr}+\mathrm{Y}$ content compared to the data measured by ToF-E ERDA. This is due to the reduced sensitivity towards light elements by the EDS technique. The relation between composition measured ToF-E ERDA and EDS was used to calibrate all subsequent EDS data to the ToF-E ERDA measurements which are more accurate with respect to oxygen.

To test the large-scale homogeneity of the coating, film composition has been measured by EDS at random positions throughout the coating height of the sputtering unit. Table I shows the calibrated film compositions. For some samples the measured composition differs slightly from the theoretical composition but the differences between the mean values are not 
statistically significant, indicating the deposited thin film is homogeneous throughout the coated area.

\section{Conclusion}

Cubic YSZ films have been deposited by reactive magnetron sputtering in an industrial coating unit. Both $\mathrm{Si}(001)$ and commercial tape cast NiO-YSZ anodes for fuel cell application have been used as substrates. Bias dependent texturing of the resulting films was observed when depositing on $\mathrm{Si}(001)$. By increasing the substrate bias voltage columnar film growth could be prevented.

Films deposited on NiO-YSZ substrates were columnar both at high and low bias voltage, but the size of the columns were dependent on substrate bias. At high bias the columns were up to 10 times wider than observed at floating potential which resulted in a denser film that might be less permeable to gas. TEM investigations showed a pronounced template effect for films grown at bias voltages $\geq-50 \mathrm{~V}$ which resulted in films having the same orientation as the underlying substrate. As the substrate consists of $\mathrm{NiO}$ and YSZ grains with random orientation no overall texture could exist in the deposited film. Films grown with a low bias voltage $(-30 \mathrm{~V})$ did not have any texture nor did they show any substrate template effect.

Furthermore, it was shown that homogenous YSZ coatings could be deposited over large areas throughout the entire coating height of the industrial unit employed in the experiments. The large scale homogeneity was observed in a coating zone equal to $80 \%$ of the target length. This is a significant finding as the prospect of producing uniform coatings across large surface areas independent of sample position in the coating unit is a precondition for the industrialization of SOFCs with sputtered thin film electrolytes. 


\section{Acknowledgments}

Financial support from Nordforsk ref. no. 9046 (ThinSOFT), Nordic Innovation Centre ref. no. 09046 (Thin-SOFC), and the Swedish Foundation for Strategic Research is gratefully acknowledged. We thank the Tandem Laboratory, Uppsala University, for access to the ERD set-up. 


\section{References:}

[1] S.J. Litzelman, J.L. Hertz, W. Jung, H.L.Tuller, Fuel Cells 8 (2008) 294-302.

[2] L. R. Pederson, P. Singh, X.-D. Zhou, Vacuum 80 (2006) 1066-1083.

[3] M. Tucker, J. Power Sources, 195 (2010) 4570-4582.

[4] D. Beckel , A. Bieberle-Hütter, A. Harvey, A. Infortuna, U.P. Muecke, M. Prestat, J.L.M. Rupp, L.J. Gauckler, J. Power Sources 173 (2007) 325-345.

[5] H. Hidalgo, E. Reguzina, E. Millon, A.-L. Thomann, J. Mathias, C. Boulmer-Leborgne, T. Sauvage, P. Brault, Surf. Coat. Technol. 205 (2011) 4495-4499.

[6] I. Kosacki, C. M. Rouleau, P. F. Becher, J. Bentley, D. H. Lowndes, Solid State Ionics 176 (2005) 1319-1326.

[7] Y. Pan, H. Zhu, M. Z. Hu, E. A. Payzant, Surf Coat Technol. 200 (2005) 1242-1247.

[8] J. H. Shim, C.-C. Chao, H. Huang, F. B. Prinz, Chem. Mater. 19 (2007) 3850-3854.

[9] A. Karthikeyan, C. Chang, S. Ramanathan, Appl. Phys. Lett., 89 (2006) 183116.

[10] M. Sillassen, P. Eklund, M. Sridharan, N. Pryds, N. Bonanos, J. Bøttiger, J. Appl. Phys., 105 (2009) 104907.

[11] S. Mahieu, P. Ghekiere, G. De Winter, D. Depla, R. De Gryse, O.I. Lebedev, G. Van Tendeloo, Thin Solid Films 484 (2005) 18-25.

[12] B. Hobein, F. Tietz, D. Stöver, M. Čekada, P. Panjan, J. Eur. Ceram. Soc. 21 (2001) $1843-1846$.

[13] F. Smeacetto, M. Salvo, L. C. Ajitdoss, S. Perero, T. Moskalewicz, S. Boldrini, L. Doubova, M. Ferraris, Mater. Lett. 64 (2010) 2450-2453.

[14] P. Briois, A. Billard, Surf. Coat. Technol. 201 (2006) 1328-1334.

[15] M. Sillassen, P. Eklund, N. Pryds, E. Johnson, U. Helmersson, J. Bøttiger, Adv. Funct. Mater. 20 (2010) 2071-2076.

[16] W. D. Sproul, D. J. Christie, D. C. Carter, Thin Solid Films 491 (2005) 1-17.

[17] J. Janek, C. Korte, Solid State Ionics 116 (1999) 181-195.

[18] H.J. Whitlow, G. Possnert, C.S. Petersson, Nucl. Instrum. Methods B 27 (1987) 448.

[19] J. Jensen, D. Martin, A. Surpi, T. Kubart, Nucl. Instrum. Methods B 268 (2010) 1893 1898.

[20] M.S. Janson, CONTES, Conversion of Time-Energy Spectra, a program for ERDA data analysis. Internal Report, Uppsala University (2004). 
[21] S. Mahieu, P. Ghekiere, G. Dewinter, S. Heirwegh, D. Depla, R. Degryse, O. Lebedev, G. Vantendeloo, J. Cryst. Growth 279 (2005) 100-109.

[22] M. Sillassen, P. Eklund, N. Pryds, J. Bøttiger, Solid State Ionics 181 (2010) 864-867.

[23] J. S. Lamas, W.P. Leroy, D. Depla, Thin Solid Films (2011) doi: 10.1016/j.tsf.2011.10.179 in press

[24] S. Mahieu, P. Ghekiere, D. Depla, R. Degryse, Thin Solid Films 515 (2006) 1229-1249.

[25] I. Petrov, P.B. Barna, L. Hultman, J.E. Greene, J. Vac. Sci. Technol., A 21 (2003) S117128. 


\section{Figure captions}

Figure 1:

Schematic drawing of the deposition geometry. NiO-YSZ substrates were mounted on a stage carrying out a two-fold planetary rotation. The substrates were mounted at different heights throughout the coating zone of the sputtering unit.

Figure 2:

$\theta-2 \theta$ x-ray diffractograms of YSZ films deposited at different substrate bias voltages on $\mathrm{Si}(001)$ substrates. Asterisks mark artifacts due to $\mathrm{Cu} K \beta$ and $\mathrm{W} L \alpha$ radiation.

Figure 3:

SEM surface micrographs of YSZ films deposited at -30 V (a), -70 V (b), and -200 V (c) bias. Substrate is $\mathrm{Si}(001)$.

Figure 4:

Cross section SEM micrographs of YSZ films deposited at -40 V (a), -50 V (b), and -200 V (c) substrate bias on $\mathrm{Si}(001)$ substrates.

Figure 5:

Cross-section SEM images of YSZ films deposited at floating potential (a) and -140 V bias (b) on NiO-YSZ anodes and cross-section TEM image of YSZ film deposited at -140 V (c).

Figure 6:

SEM micrographs showing the surface of and uncoated NiO-YSZ anode (a), an NiO-YSZ anode coated at floating potential (b), and at $-140 \mathrm{~V}$ substrate bias (c).

Figure 7:

TEM micrographs and electron diffraction patterns of YSZ grown at $-50 \mathrm{~V}$ substrate bias on a YSZ grain (a) and a $\mathrm{NiO}$ grain (b) found in the NiO-YSZ anode substrate. In (a) electron diffraction along the [112] zone axis is shown for the YSZ grain and two locations in the film. In (b) electron diffractogram along the [011] zone axis is shown for the interface between the substrate and the film. A square and a circle mark the spots from YSZ and NiO, respectively.

Figure 8:

TEM micrograph and electron diffraction patterns of YSZ grown at $-30 \mathrm{~V}$ substrate bias on a YSZ grain found in the NiO-YSZ substrate. 


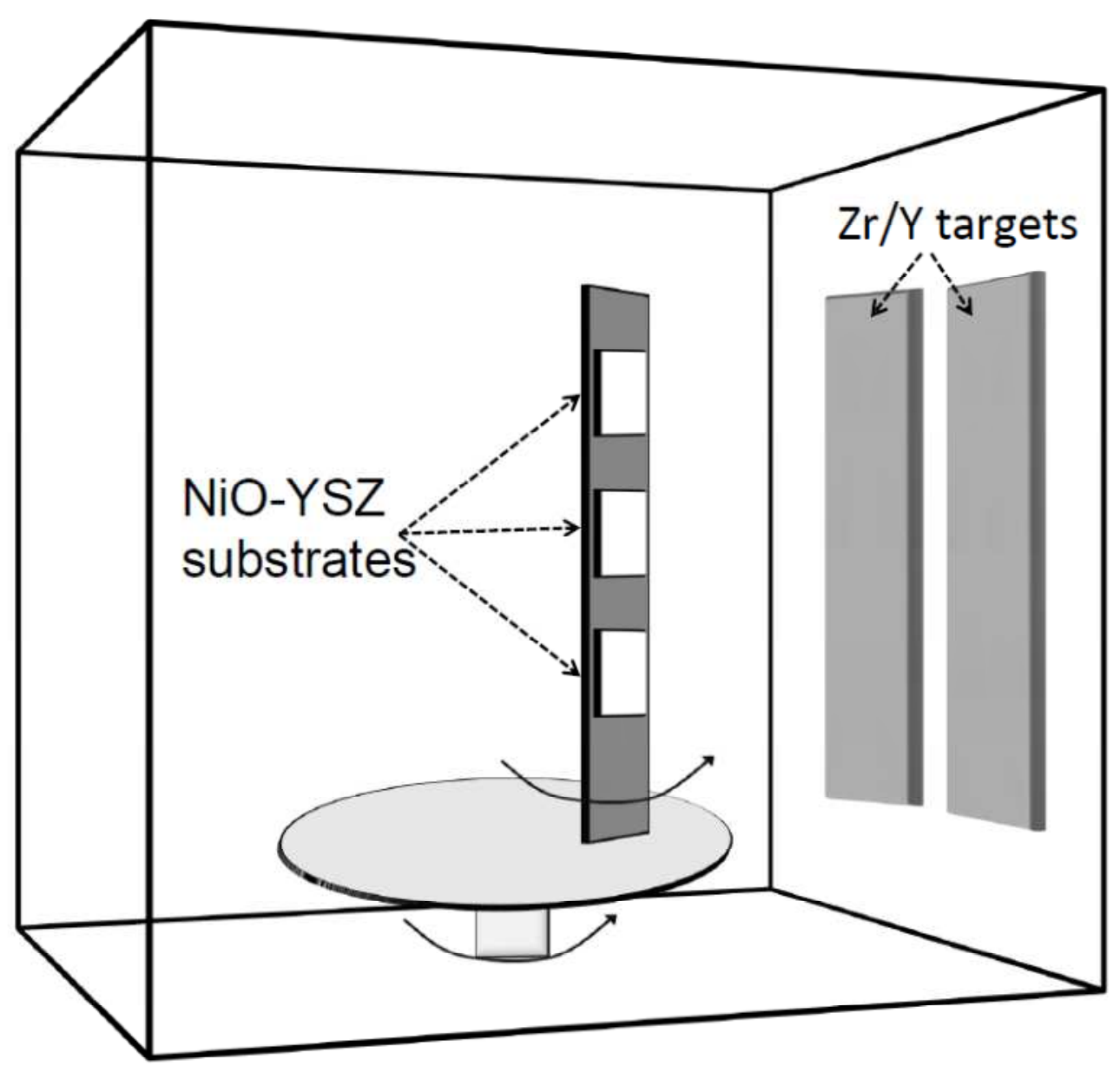

Fig. 1 


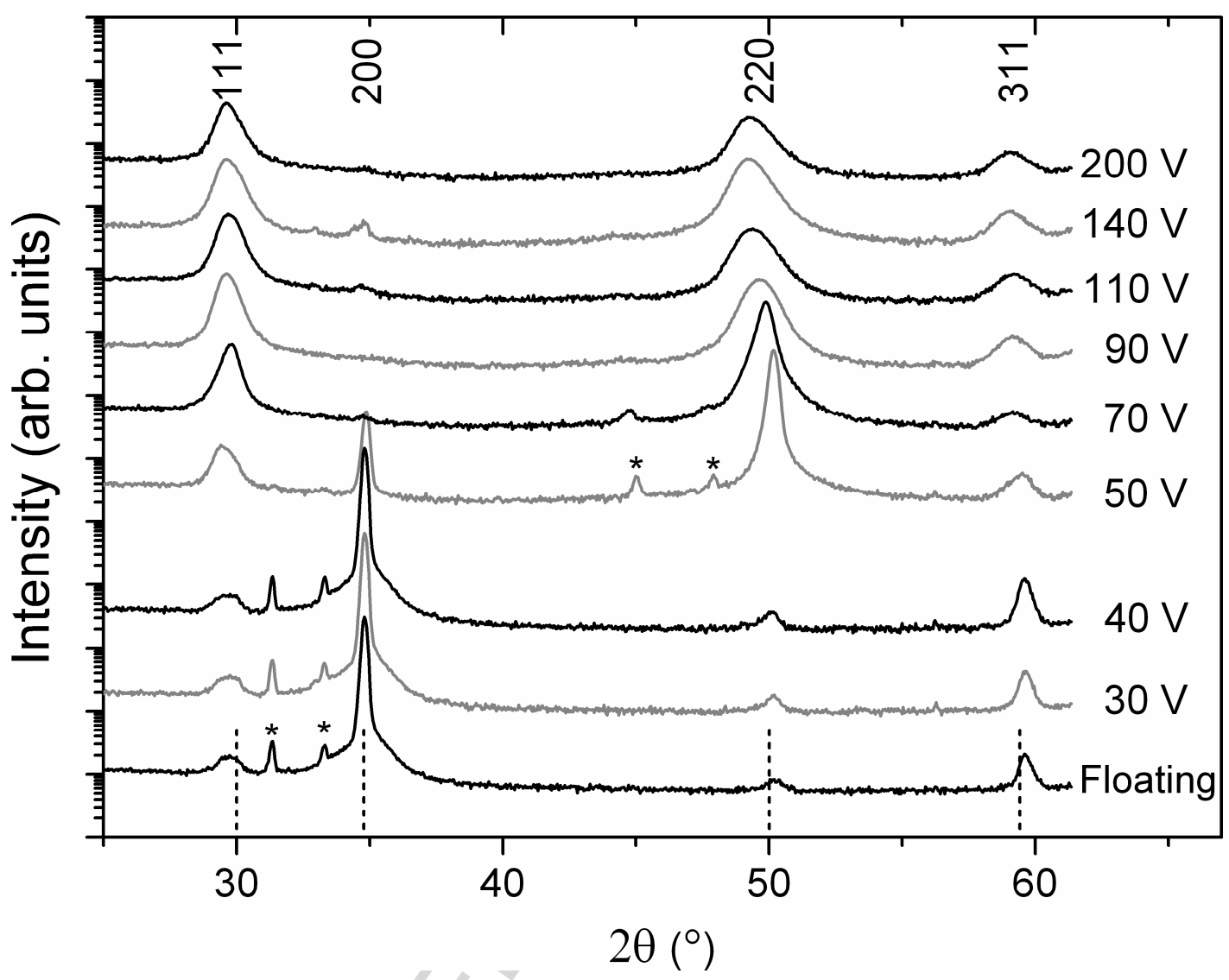

Fig. 2 

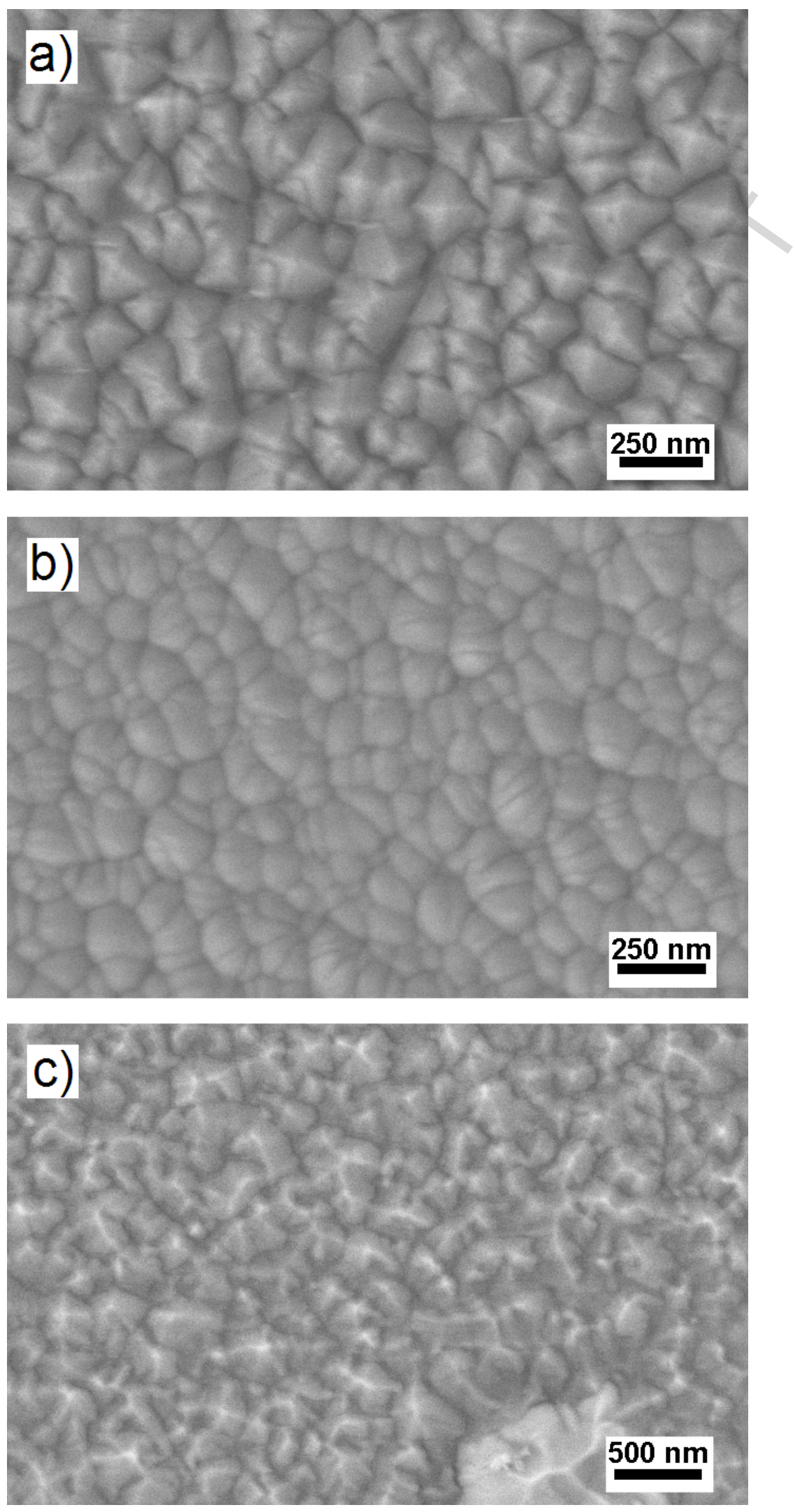

Fig. 3 


\section{ACCEPTED MANUSCRIPT}
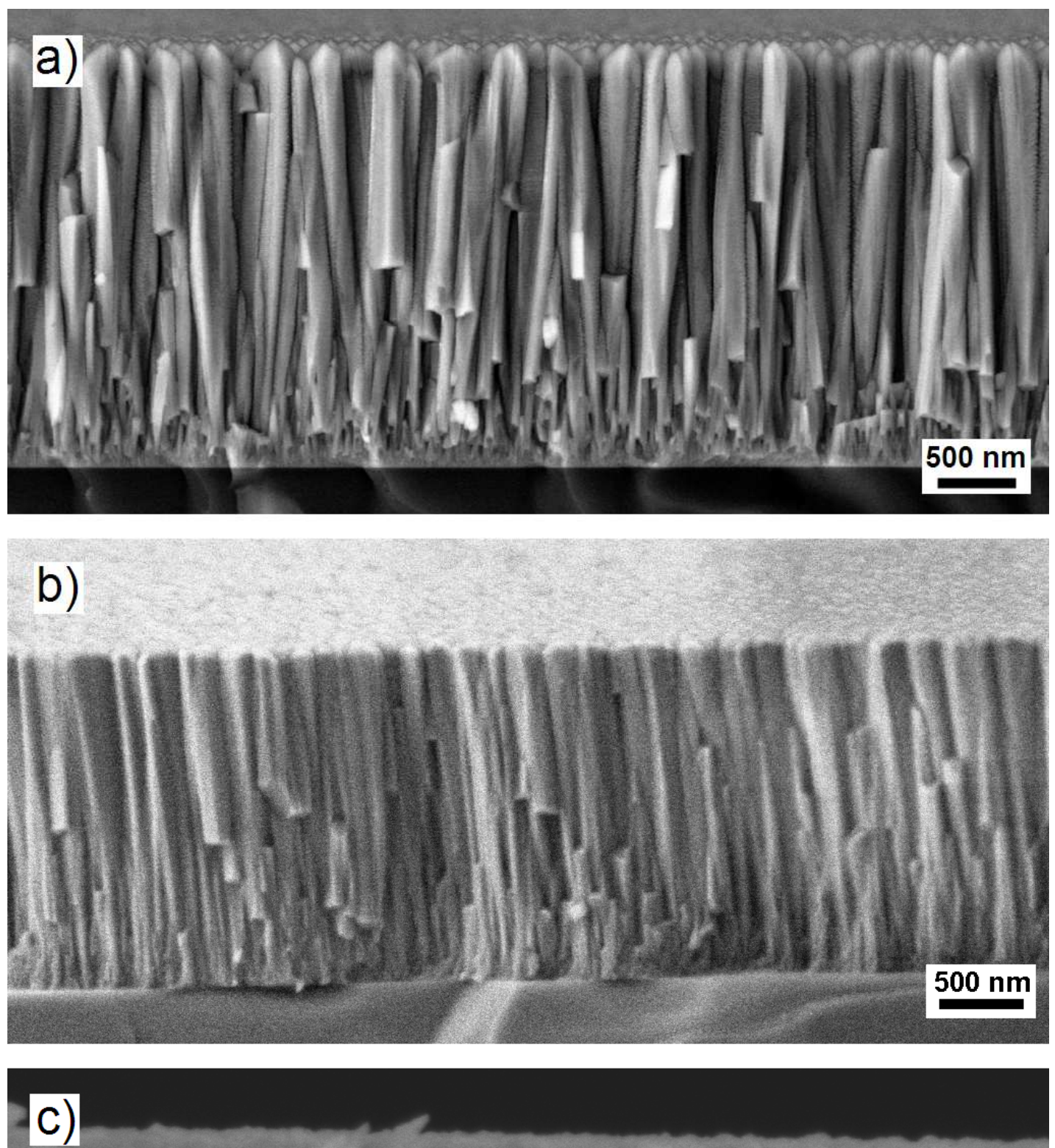

Fig. 4 

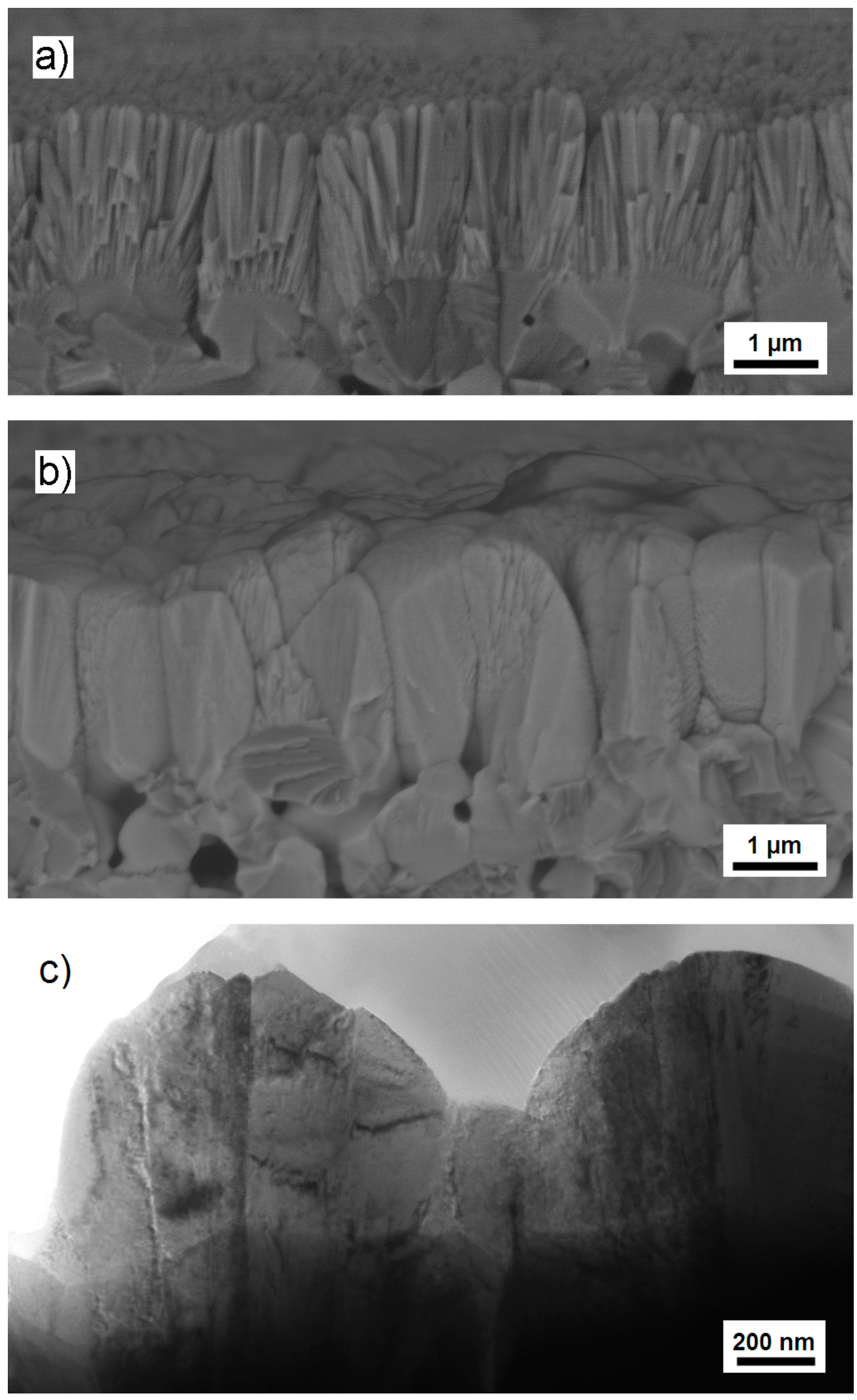

Fig. 5 

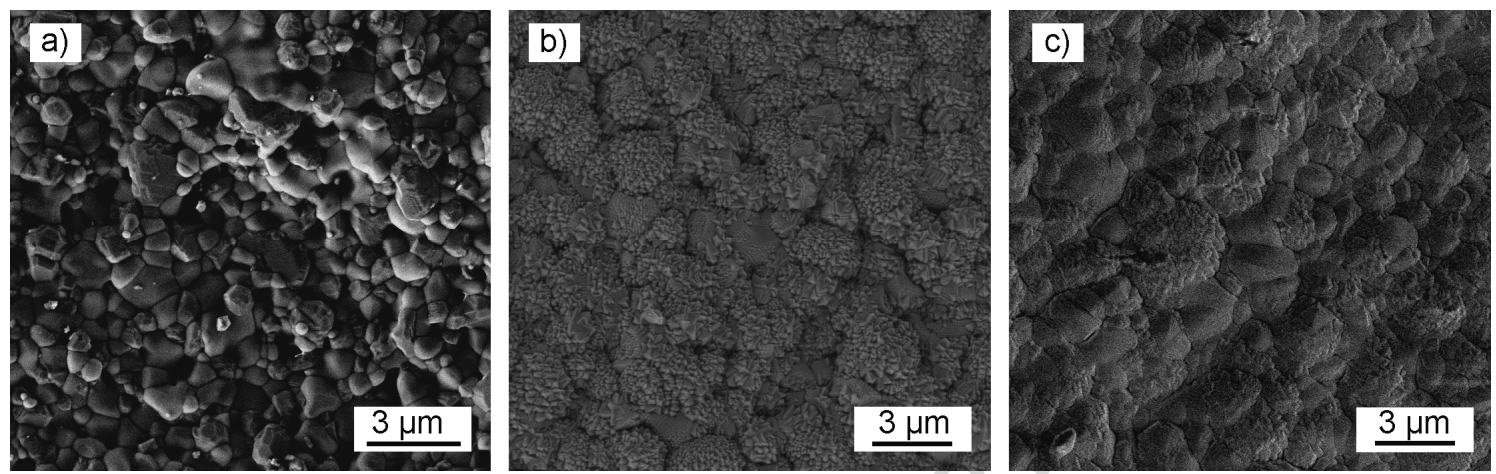

Fig. 6 


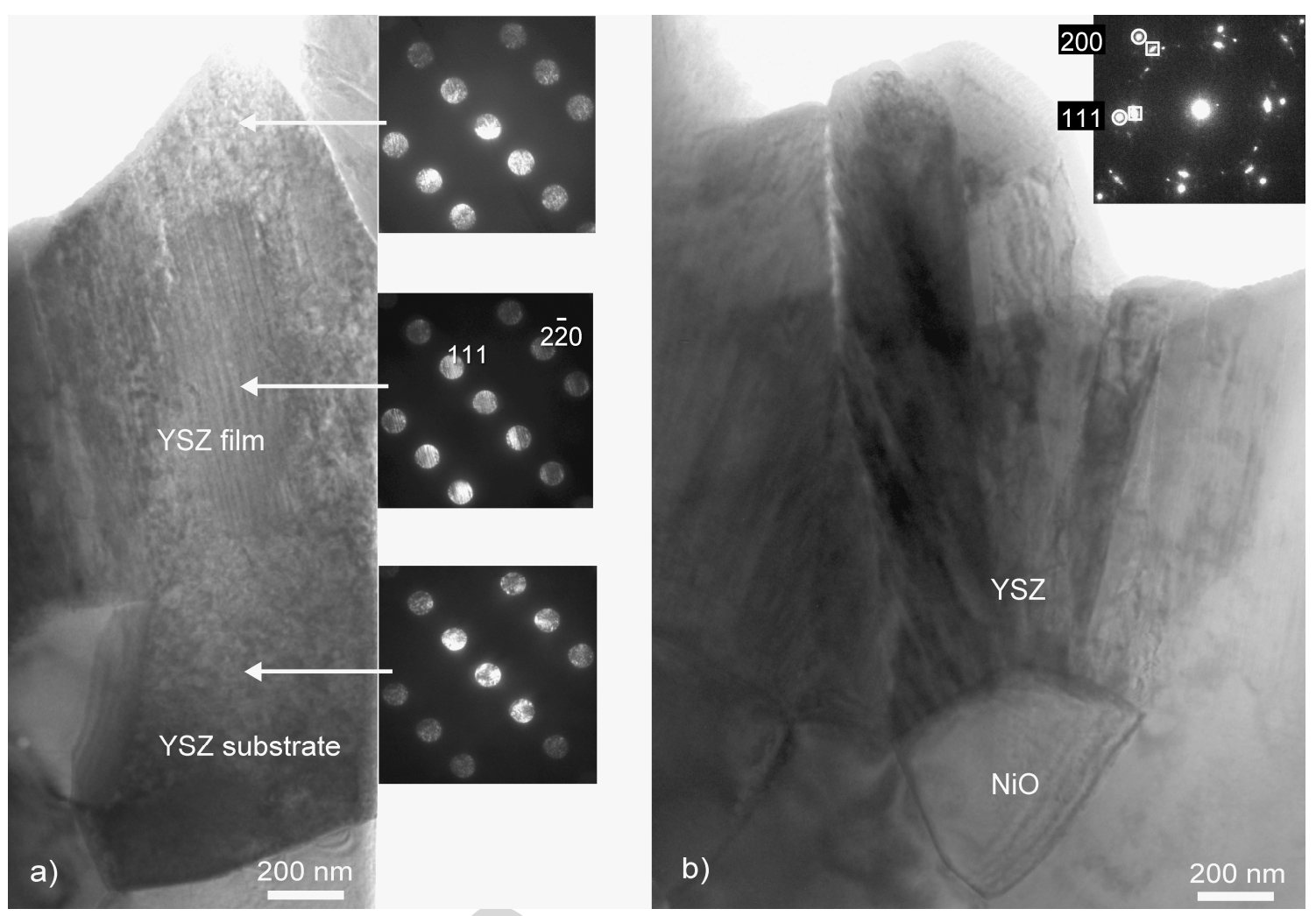

Fig. 7 


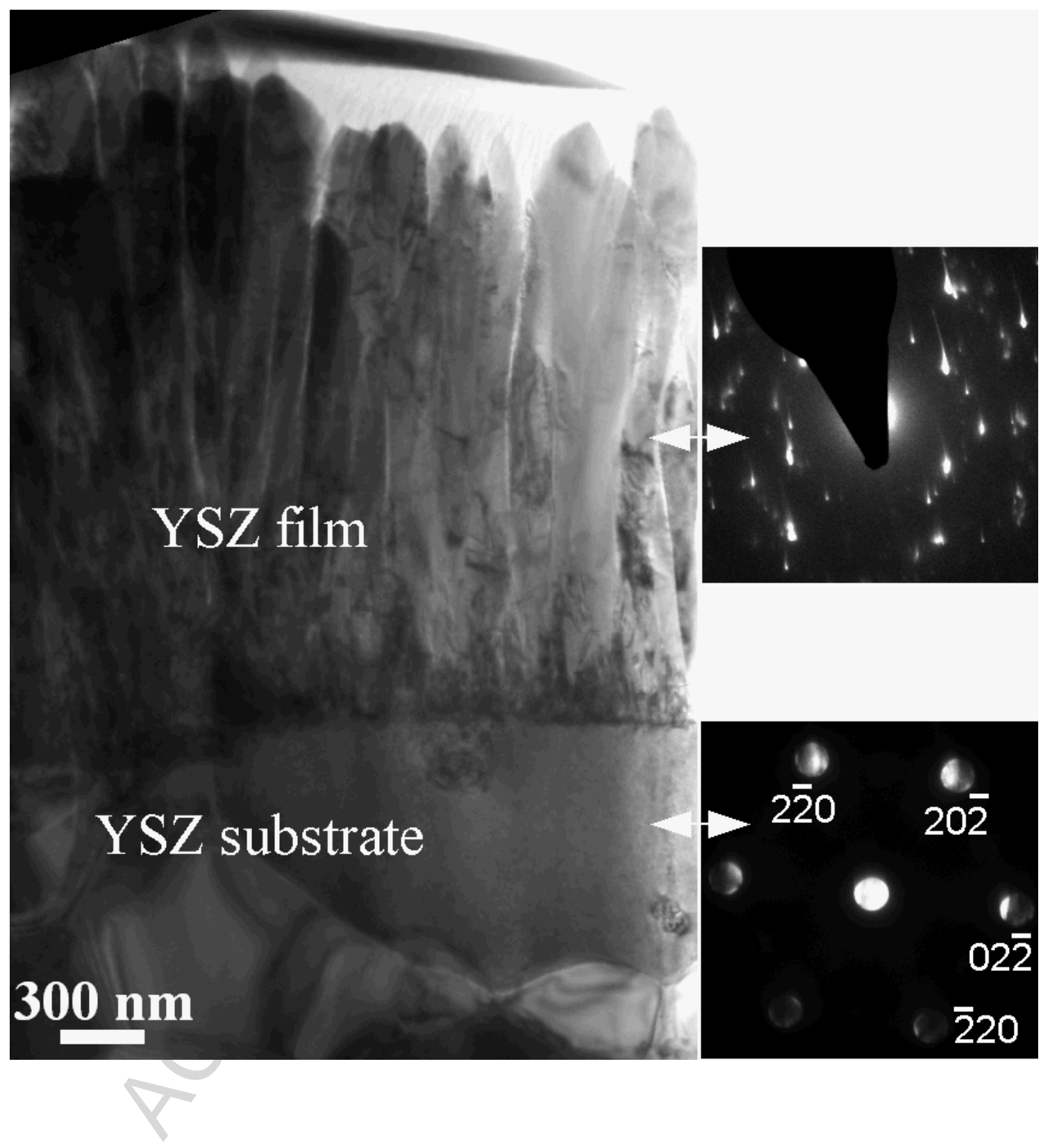

Fig. 8 
Table I

Film composition measured by EDS at different positions in the chamber setup. The data has been calibrated to fit the ERDA measurements. The analyzed areas are randomly chosen throughout the coating height of the sputtering unit. Data shown as mean value \pm standard deviation. Mean values are not statistically significantly different as $\mathrm{P}>0.05$ in all cases.

\begin{tabular}{c|c|c|c|c|c|c|c|c|c} 
& \multicolumn{3}{|c|}{ Sample 1 } & \multicolumn{3}{c|}{ Sample 2 } & \multicolumn{3}{c}{ Sample 3 } \\
\hline & $\begin{array}{c}\text { point } \\
\text { no. 1 }\end{array}$ & $\begin{array}{c}\text { point } \\
\text { no. 2 }\end{array}$ & $\begin{array}{c}\text { point } \\
\text { no. 3 }\end{array}$ & $\begin{array}{c}\text { point } \\
\text { no. 4 }\end{array}$ & $\begin{array}{c}\text { point } \\
\text { no. 5 }\end{array}$ & $\begin{array}{c}\text { point } \\
\text { no. 6 }\end{array}$ & $\begin{array}{c}\text { point } \\
\text { no. 7 }\end{array}$ & $\begin{array}{c}\text { point } \\
\text { no. 8 }\end{array}$ & $\begin{array}{c}\text { Piont } \\
\text { no. 9 }\end{array}$ \\
\hline $\begin{array}{c}\text { Y } \\
\text { at.\%) }\end{array}$ & $5.4 \pm 0.3$ & $5.2 \pm 0.04$ & $5.3 \pm 0.1$ & $5.4 \pm 0.2$ & $5.4 \pm 0.3$ & $5.4 \pm 0.4$ & $5.5 \pm 0.1$ & $5.5 \pm 0.2$ & $5.4 \pm 0.2$ \\
\hline $\begin{array}{c}\mathrm{Zr} \\
\text { at.\%) }\end{array}$ & $27.8 \pm 0.7$ & $27.5 \pm 0.3$ & $27.7 \pm 0.6$ & $27.9 \pm 1.4$ & $28.1 \pm 2.2$ & $28.0 \pm 2.1$ & $27.9 \pm 0.6$ & $27.6 \pm 0.7$ & $27.1 \pm 0.5$ \\
\hline $\begin{array}{c}\text { O } \\
(\text { at.\%) }\end{array}$ & $65.9 \pm 0.9$ & $66.5 \pm 0.3$ & $66.4 \pm 0.3$ & $65.8 \pm 2.0$ & $65.4 \pm 3.2$ & $65.7 \pm 3.3$ & $65.6 \pm 0.8$ & $66.0 \pm 1.1$ & $66.7 \pm 0.8$
\end{tabular}




\section{Highlights}

- Tailoring of texture and morphology of YSZ films grown on Si by substrate bias.

- Films deposited on commercial NiO-YSZ shows pronounced substrate template effects.

- Uniform YSZ coatings can be deposited over large areas in an industrial setup. 